Changes in food resources and conservation of scarab beetles From sheep to dog dung in a green urban area of Rome (Coleoptera, Scarabaeoidea)

Carpaneto, Giuseppe Maria; Mazziotta, Adriano; Piattella, Emanuele

Published in:

Biological Conservation

DOI:

10.1016/j.biocon.2004.12.007

Publication date:

2005

Document version

Publisher's PDF, also known as Version of record

Citation for published version (APA):

Carpaneto, G. M., Mazziotta, A., \& Piattella, E. (2005). Changes in food resources and conservation of scarab beetles: From sheep to dog dung in a green urban area of Rome (Coleoptera, Scarabaeoidea). Biological Conservation, 123(4), 547-556. https://doi.org/10.1016/j.biocon.2004.12.007 


\title{
Changes in food resources and conservation of scarab beetles: from sheep to dog dung in a green urban area of Rome (Coleoptera, Scarabaeoidea)
}

\author{
Giuseppe Maria Carpaneto ${ }^{\mathrm{a}, *}$, Adriano Mazziotta ${ }^{\mathrm{a}}$, Emanuele Piattella ${ }^{\mathrm{b}}$ \\ a Dipartimento di Biologia, Università degli Studi "Roma Tre", Viale G. Marconi 446, 00146 Roma, Italy \\ b Dipartimento di Biologia Animale e dell Uomo, Università di Roma "La Sapienza", Viale dell Università 32, 00185 Roma, Italy
}

Received 28 June 2004; received in revised form 2 December 2004; accepted 10 December 2004

\begin{abstract}
The aim of the research was to show how a change in land use influences the structure of a dung beetle assemblage and affect its conservation. In the Pineto Urban Regional Park (Rome), dog dung is the sole food resource currently available for scarab dung beetles, after the recent removal of wild and domestic herbivores. A one-year sampling was conducted to study the scarab assemblage in dog scats (1999) and to compare it with the previous assemblage associated with sheep droppings (1986). Richness, evenness and similarity parameters were compared between the two allochronic assemblages. From sheep to dog dung, an impoverishment of the total richness was observed (from 19 to 9 species) together with an increase of individuals (by 7 times). Dog dung harboured $20 \%$ of the current scarab dung beetle fauna of Rome, probably as a consequence of the dog mixed diet, rich in cellulose. Both the communities showed a high percentage of tunnellers, probably because of the food shortage and, for dog scats, of the high dehydration rate. A comparison with other Roman scarab communities enhanced that: (1) the change in food resource determined a higher difference in species composition respect to other parameters (size and habitat diversity); (2) dog dung provided a temporary refuge for species that otherwise may encounter local extinction in urban environments.
\end{abstract}

(c) 2005 Elsevier Ltd. All rights reserved.

Keywords: Urban ecology; Community ecology; Biodiversity conservation; Food resources; Dung beetle assemblages

\section{Introduction}

Information about insect population decline is still scarce respect to that recorded for plant and vertebrate species. A low number of studies was conducted in North America and Europe to emphasise changes in composition of insect communities and their population decline through a long-term period (e.g., Desender and Turin, 1989; Lobo, 2001; Pyle et al., 1981; Turin and den Boer, 1988; van Swaay, 1990).

\footnotetext{
321.

* Corresponding author. Tel.: +39655176 328; fax: +39655176

E-mail address: carpanet@uniroma3.it (G.M. Carpaneto).
}

The conservation of dung beetle communities in green urban areas is strongly affected by reduction to complete disappearance of grazing herbivores. In many cases, the lands which were previously used as pastures were reconverted to green areas for recreational purposes while two species of carnivores, dogs and cats (both domestic and feral) became the most common large mammals.

The dung of carnivorous mammals is hardly colonised by Palaearctic scarab beetles (Barbero et al., 1999; Mysterud and Wiger, 1976; Carpaneto and Fabbri, 1984; Hancox, 1991; Halffter and Matthews, 1966; Martin-Piera and Lobo, 1996). Apart from a small number of truly generalist species, dung beetles usually avoid 
the faeces of wild carnivores because these are poor in cellulose content (M. Salonen in Landin, 1961). Only the brown bear (Ursus arctos Linnaeus, 1758), owing to its omnivorous diet, harbours a rich community of these insects (Carpaneto and Fabbri, 1984).

Data on the exploitation of dog scats as food resources for scarab beetles are few and scattered (e.g., Faithfull, 1992, 1994; Fincher et al., 1970; Huang et al., 2001; Oppenheimer and Begum, 1978). The study area of the present paper (the Urban Regional Park of Pineto) is a green patch entrapped within the town of Rome since many decades and was intensively grazed by sheep up to 1989, when it was reconverted into a public recreational area. As a consequence of the new management, grazing was suspended and dogs became the only large mammals. The elimination of livestock was the only great change operated in this area and around it during such passage from grazing to recreational use. In 1986, a one-year sampling was conducted in order to study the species composition and dynamics of the dung beetles community associated to ovine droppings (Carpaneto and Piattella, 1990) when the latter was the only steady resource of food available for dung beetles. Since then, dog scats are the only present source of food for dung beetles, as just occurred in other European and Australian capitals (Faithfull, 1992). Nowadays, some dogs are feral or vagrant, while the others are regularly brought there by their owners from the neighbouring houses.

The aim of the present study is to compare the past and present diversity of species in the dung beetle community of this area in order to discuss changes in their food resource. There have been few attempts to investigate the dung beetle preference for different types of dung, and the results are often contradictory (Barbero et al., 1999; Gittings and Giller, 1998; Lumaret et al., 1992). In particular, the objectives of this paper are: (1) to estimate the modifications in species assemblage with the change in resource quality and land use; (2) to test if changes in dung type produced variations in the proportional abundance of the species; (3) to understand if scarab beetle species are able to survive by exploiting dog dung as food resource in unchanged environmental conditions, after sheep removal.

\section{Methods}

\subsection{Study areas}

The main study area represents a fragment of Roman countryside entrapped by the unplanned urban development of the Fifties. It was preserved by the institution of the Urban Regional Park of Pineto, established in 24 September 1986. The area lies in the NW part of Rome and covers about 240 ha. The current landscape consists of small deciduous woodlands and grasslands extended over an undulated surface of low hills, including both volcanic and alluvial soils. Some perennial streams and ponds occur in the area as well as some artificial stands of pine trees. In the Roman toponymy, a large part of this site is called "Valle dell'Inferno" or "Valle Aurelia".

Moreover, other nine green areas (parks) of Rome were considered for a comparison: seven in urban and two in suburban (Decima Malafede Natural Reserve and Marcigliana Natural Reserve) sectors of the town. These parks are characterised by a different extension (from a minimum of 60 ha in Aguzzano Urban Regional Park to a maximum of 6.145 ha in Decima Malafede Natural Reserve) (Table 1) and by similar open grasslands exploited by ovine livestock. All the parks lay at the same altitude above sea level, and are crossed by

Table 1

Species richness and abundance of dung beetle assemblages in the nine Roman parks (sampled in 1999)

\begin{tabular}{|c|c|c|c|c|c|c|c|c|c|}
\hline \multirow[t]{2}{*}{ Park } & \multirow[t]{2}{*}{ Extension (ha) } & \multicolumn{4}{|c|}{ Richness } & \multicolumn{4}{|c|}{ Abundance } \\
\hline & & $\mathrm{S}$ & $\mathrm{H}$ & C & Total & $\mathrm{S}$ & $\mathrm{H}$ & C & Total \\
\hline MAR & 4696 & 27 & 19 & 26 & 37 & 2486 & 514 & 439 & 3439 \\
\hline ANI & 620 & 24 & 7 & - & 24 & 1348 & 36 & - & 1384 \\
\hline DEC & 6145 & 31 & 24 & 26 & 37 & 2619 & 539 & 315 & 3473 \\
\hline MAS & 774 & 23 & - & - & 23 & 1526 & - & - & 1526 \\
\hline CAS & 469 & 16 & 7 & - & 17 & 884 & 77 & - & 961 \\
\hline ACQ & 249 & 26 & - & - & 26 & 1063 & - & - & 1063 \\
\hline INS & 697 & 23 & 25 & - & 30 & 1696 & 327 & - & 2023 \\
\hline AGU & 60 & 22 & 1 & - & 22 & 1818 & 103 & - & 1921 \\
\hline APP & 3500 & 21 & - & - & 21 & 1718 & - & - & 1718 \\
\hline Total & 17,210 & 39 & 36 & 35 & 45 & 15,158 & 1596 & 754 & 17,507 \\
\hline
\end{tabular}

(Acronyms of the parks: AGU, Aguzzano Urban Regional Park; ANI, Natural Reserve of Valle dell'Aniene; ACQ, Natural Reserve of Tenuta dell'Acquafredda; APP, Appia Antica Regional Park; CAS, Natural Reserve of Valle dei Casali; DEC, Natural Reserve of Decima Malafede; INS, Natural Reserve of Insugherata; MAR, Natural Reserve of Marcigliana; MAS, Natural Reserve of Tenuta dei Massimi; S, sheep; H, horse; C, cow; -, no data). For a comparison, in the Pineto Park in sheep dung (1986) the rarefaction curve estimated 18 species for a sample size of 210 individuals. 
many small streams, all tributaries of Tevere and Aniene rivers. The name of the other study areas were abbreviated as follows: AGU, Aguzzano Urban Regional Park; ANI, Natural Reserve of Valle dell'Aniene; ACQ, Natural Reserve of Tenuta dell'Acquafredda; APP, Appia Antica Regional Park; CAS, Natural Reserve of Valle dei Casali; DEC, Natural Reserve of Decima Malafede; INS, Natural Reserve of Insugherata; MAR, Natural Reserve of Marcigliana; MAS, Natural Reserve of Tenuta dei Massimi; PIN, Pineto Urban Regional Park.

Climatic data for the Pineto Park in the years 1986 and 1999, i.e., maximum, minimum, mean temperatures and precipitations, were collected from the meteorological observatory "Torre Calandrelli" located in the Roman College, located in the city centre $(66.4 \mathrm{~m}$ a.s.l., $41^{\circ} 53^{\prime} 54^{\prime \prime} \mathrm{N}, 12^{\circ} 28^{\prime} 50^{\prime \prime} \mathrm{E}$ ).

\subsection{Sampling method}

Sampling in the Pineto Park was made from January to December both in 1986 (sheep dung) and in 1999 (dog dung); in the other nine Roman urban areas used for comparison, samples were mostly from sheep but also from cow and horse dung, from January to December 1999. During all the samples, scats were crumbled and washed into a bucket full of water, and beetles collected by a small sieve.

Monthly samples consisted of about 51 of dung, collected at morning (10:00-11:00) from each area. A quantity of 51 was established because it was the minimum volume of dung regularly occurring each month in the study areas (unpublished data).

Moreover, a rarefaction curve in sheep dung was accomplished for both each area and the total sample

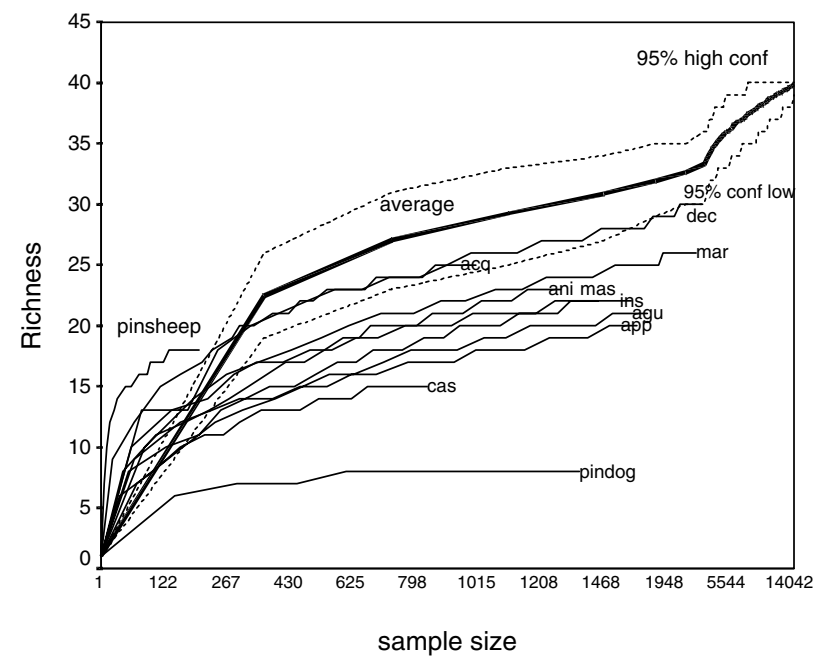

Fig. 1. Rarefaction curves for the total dung beetle sample from sheep dung in nine protected areas of Rome in 1999, and rarefaction curves for all the 10 protected areas including Pineto Park in 1986 (sheep dung) and in 1999 (dog dung).
(Fig. 1). Richness is dependent on both sample size (i.e., the number of specimens in a collection) and the relative abundances of the component taxa. In order to compare samples of different size, it is necessary to calculate their expected richness at a standardised size, which is the purpose of rarefaction (Sanders, 1968; Hurlbert, 1971; Heck et al., 1975). Rarefaction curves based on the hypergeometric distribution assume sub-sampling of a collection without replacement (Olszewski, 2004). Rarefaction answers this question: if the sample had consisted of $n$ individuals $(n<N)$, what number of species(s) would likely have been seen? Note that if the total sample has $S$ species and $N$ individuals, the rarefied sample must always have $n<N$ and $s<S$. High and low 95\% confidence intervals were associated with each calculated value of average richness at a certain sample size for the entire regional species pool (i.e., the entire sampling in sheep dung for all the sample areas) using EcoSim 700 (http://www.homepages.together.net/ gentsmin/ ecosim.htm). The differences in diversity between areas were explored by calculating the estimated number of species by rarefaction at the minimum number of individuals.

Moreover, a measure of evenness $\left(\Delta_{1}=\right.$ Hurlbert's probability of interspecific encounter) was associated with each sample. This index can be interpreted as the probability that the second specimen randomly picked from a sample (without replacement of the first specimen) will be of the same species as the first specimen. This metric is not biased by sample size or species richness and ranges from 0 to 1 . It was described as follows:

$\Delta_{1}=\frac{N}{N-1}\left(1-\sum_{j=1}^{S} p_{j}^{2}\right)$,

where $N$ is the number of specimen in entire sample (i.e., local sample size)

$p_{j}=\frac{n_{j}}{N}=$ proportion of species $j$ in a sample.

Sample size and species richness between the two allochronic assemblages in the Pineto Park were tested by a $\chi^{2}$ test, with Yates' correction for continuity, considering as null-hypothesis an equal number of individuals and species expected in both the assemblages.

\subsection{Data analysis}

The importance of each species in the structure of the whole community was considered as the consequence of two jointed factors: ranked abundance and adult phenol$o g y$. The ranked abundance (degree of dominance in the assemblage) was calculated as the rank acquired by each species, based on the number of individuals. Species adult phenology was merely the number of months in 
which the adults of each species were observed during the year. The numerical importance of each family was calculated as percentage of occurrence, i.e., the percentage of the number of species belonging to each family respect to the total number of species.

Adult phenologies of scarab beetles (at generic rank) and correlations between species abundance and climatic parameters were analysed by Spearman's rank correlation test, differences in richness and diversity mean values by paired-samples $t$ test and differences in richness median values by Wilcoxon Signed Ranks Test. All these tests were performed using SPSS software (version 8.0). Significant level was fixed to $p \leqslant 0.05$.

The Shannon's diversity index was used as a measure for community diversity for each monthly sampling, $H^{\prime}=-\sum_{i} p_{i} \log _{\mathrm{e}} p_{i}$, where $p_{i}$ is the proportion of individuals belonging to species $i$ in a sampling. The evenness was calculated by the Pielou's index, $J^{\prime}=H^{\prime} / \log _{\mathrm{e}} S$, where $S$ is the number of species in the sampling. Similarity of scarab assemblages among different pairs of dung types was analysed using the Jaccard's index, $[c /(a+b-c)] \times 100$, where $a$ and $b$ are the number of species for the two dung types compared, and $c$ is the number of species shared by them, to obtain a distance matrix. Distances were clustered according to UPGMA (unweighted pair-group method using arithmetical averages) amalgamation rule using Statistica 6.0.

The data resulting from the dog scat sampling of the present research, were compared with the past data reported by Carpaneto and Piattella (1990) from sheep dung sampling, in order to assess the zoocenotic changes.

From a functional point of view, in order to assess the differences in life-history strategies between the two scarab communities, a comparison was done between the percent occurrence of species with different habits of dung utilisation (Cambefort and Hanski, 1991; Finn and Gittings, 2003):

- Tunnellers (paracoprids): geotrupids, many scarabaeines (Copris, Chironitis, Bubas, Euoniticellus, Caccobius, Euonthophagus, Onthophagus) and some Aphodiidae (in particular: Aphodius erraticus, see Rojewski, 1983 and Vitner, 1998) which dig chambers under the pat and bring dung inside for feeding or breeding.

- Rollers (telecoprids): other scarabaeines (Scarabaeus, Gymnopleurus, Sisyphus) which form a ball of dung that can be rolled away from the pat and buried for feeding or breeding.

- Dwellers (endocoprids): almost all Aphodiidae, which feed in the dung pat as adults and lay eggs within or under the dung mass where they undergo larval development.
Finally, the scarab community associated to dog scats in the main study area was compared with other nine communities studied in other protected areas of Rome, all characterised by the occurrence of sheep.

\section{Results}

\subsection{Richness, diversity and dominance}

Nine coprophagous species associated with dog scats were gathered during the sampling. The number of species associated with dog scats deals with $12 \%$ of the whole scarab dung beetle fauna (75 species) recorded still now from the urban area of Rome (Carpaneto and Piattella, 1997). Nevertheless, they represent 20\% of the current dung beetle fauna of the urban area of Rome ( 45 species) as resulted by a recent and comprehensive research conducted in all the other nine Roman parks from 1999 to 2000. The number of species occurring in these areas in sheep dung, varies from 16 to 31 $($ median value $=23.0,25$ th percentile $=21.5,75$ th percentile $=26.5$ ).

The sample effort to compare species richness among the above-mentioned areas was verified through the rarefaction method (Sanders, 1968). Only for few areas, the rarefaction curve was comprised in the calculated interval of variation, corresponding to values of $\Delta_{1}$ higher than $\Delta_{1}$ for the entire species pool $(0.77055): \Delta_{1}(\mathrm{ANI})=0.79952$, $\Delta_{1}(\mathrm{DEC})=0.82371, \quad \Delta_{1}(\mathrm{ACQ})=0.79687, \quad \Delta_{1}(\mathrm{PIN}-$ sheep $)=0.89774$. The majority of the other areas presented a less steep rising limb of the rarefaction curve, neatly lower than that one observed for average richness (i.e., for the entire regional species pool), corresponding to values of $\Delta_{1}$ lower than $\Delta_{1}$ for the entire species pool: $\Delta_{1}(\mathrm{MAR})=0.67582, \quad \Delta_{1}(\mathrm{MAS})=0.62460, \quad \Delta_{1}(\mathrm{CAS})=$ $0.61196, \quad \Delta_{1}(\mathrm{INS})=0.71408, \quad \Delta_{1}(\mathrm{AGU})=0.38887$, $\Delta_{1}(\mathrm{DEC})=0.71135, \Delta_{1}(\mathrm{PINdog})=0.31915$. For the total sampling, the estimated number of species by rarefaction at the minimum number of individuals amounted to 22.45 species for a sample size of 371 individuals. For dog dung in the Pineto Park (1999), the same value was 6 for 151 individuals, very low in comparison with all the other sheep dung data, which range from seven species for 12 individuals in the Pineto Park (1986) to 10 species for 90 individuals in MAR.

Some differences come out from the comparison between the two allochronic dung beetle communities sampled in the Pineto Park, respectively, in 1986 (sheep dung: Carpaneto and Piattella, 1990) and 1999 (dog dung: present paper) (Table 2):

(1) The total richness passes from 19 to 9 species and the total number of individuals sampled per year passes from 210 to 1498 . 
Table 2

Number of individuals, ranked abundance and adult phenology (see Section 2) for each species collected in sheep dung in the main study area in 1986 (Carpaneto and Piattella, 1990) and in dog scats in 1999 (present paper) (Tot, total number of individuals for each species)

\begin{tabular}{|c|c|c|c|c|c|c|}
\hline \multirow[t]{2}{*}{ Species } & \multicolumn{3}{|c|}{1986} & \multicolumn{3}{|l|}{1999} \\
\hline & Tot & Rank & Months & Tot & Rank & months \\
\hline Thorectes intermedius & 15 & 5 & 2 & 0 & - & - \\
\hline Aphodius convexus & 8 & 10 & 2 & 0 & - & - \\
\hline Aphodius consputus & 47 & 1 & 7 & 134 & 2 & 6 \\
\hline Aphodius erraticus & 6 & 11 & 2 & 2 & 9 & 2 \\
\hline Aphodius foetidus & 0 & - & - & 2 & 9 & 1 \\
\hline Aphodius johnsoni & 1 & 19 & 1 & 1227 & 1 & 5 \\
\hline Aphodius lineolatus & 17 & 4 & 6 & 36 & 4 & 3 \\
\hline Aphodius luridus & 27 & 2 & 2 & 0 & - & - \\
\hline Aphodius merdarius & 2 & 18 & 2 & 0 & - & - \\
\hline Aphodius quadrimaculatus & 12 & 7 & 2 & 0 & - & - \\
\hline Scarabaeus laticollis & 3 & 15 & 2 & 0 & - & - \\
\hline Bubas bison & 2 & 18 & 2 & 0 & - & - \\
\hline Euoniticellus fulvus & 8 & 10 & 4 & 0 & - & - \\
\hline Onthophagus coenobita & 5 & 12 & 3 & 53 & 3 & 4 \\
\hline Onthophagus furcatus & 11 & 8 & 3 & 0 & - & - \\
\hline Onthophagus grossepunctatus & 13 & 6 & 3 & 10 & 7 & 3 \\
\hline Onthophagus opacicollis & 2 & 18 & 1 & 0 & - & - \\
\hline Onthophagus ruficapillus & 4 & 13 & 1 & 13 & 6 & 3 \\
\hline Onthophagus taurus & 24 & 3 & 5 & 21 & 5 & 5 \\
\hline Onthophagus vacca & 3 & 15 & 2 & 0 & - & - \\
\hline Number of individuals & 210 & & & 1498 & & \\
\hline Number of species & 19 & & 9 & & & \\
\hline Number of genera & 6 & & 2 & & & \\
\hline
\end{tabular}

(2) $\mathrm{A} \chi^{2}$ test defined a significant difference between the number of species $\left(\chi^{2}=7.45, n=1, p<0.01\right)$ and the sample size $\left(\chi^{2}=971.28, \quad n=1, \quad p<0.01\right)$ between sheep and dog dung.

(3) Eight species are shared by the two allochronic communities (Table 2): Onthophagus coenobita, $O$. grossepunctatus, O. ruficapillus, O. taurus, Aphodius consputus, A. erraticus, A. johnsoni, A. lineolatus.

(4) In 1986 (sheep dung), there were 11 exclusive species (i.e., not observed in dog dung) (Table 2): Thorectes intermedius, Aphodius convexus, A. luridus, $A$. merdarius, A. quadrimaculatus, Scarabaeus laticollis, Bubas bison, Euoniticellus fulvus, Onthophagus furcatus, O. opacicollis, O. vacca.

(5) One species, Aphodius foetidus, among those collected in the present sampling (1999, dog dung) was not found in the former sampling (1986, sheep dung) (Table 2).

(6) The median number of species per month passed from $4.0(25$ th percentile $=2,75$ th percentile $=6.5)$ to $3.0(25$ th percentile $=1.25,75$ th percentile $=3.75)$ $\left(T_{10}=9, p>0.05\right.$, Wilcoxon Signed Ranks Test).

(7) The median of the monthly diversity index, decreased from 1986 to $1999\left(H_{1986}^{\prime}\right.$ median value $=1.237,25$ th percentile $=0.409,75$ th percentile $=1.559 ; H_{1999}^{\prime}=0.462,25$ th percentile $=0.016$, 75 th percentile $=0.883)\left(T_{12}=6, p<0.02\right.$, Wilcoxon Signed Ranks Test).
An increased ranked abundance, passing from sheep (1986) to dog dung (1999), only concerned some species: A. johnsoni (i.e., from 19th (last) to 1st rank), $O$. coenobita (i.e., from 12 th to 3 rd rank) and $O$. ruficapillus (i.e., from 13th to 6th rank) (Table 2). In particular, for A. johnsoni, in 1999, the rank analysis between the monthly abundance for this species and the monthly abundance for all the dung beetle species was directly significant $\left(r_{\mathrm{s}}=0.733, p=0.007\right)$. On the contrary, none rank correlation was registered in 1986, in spite of the direct correlation between the annual trend in temperature between the two years (mean, $r_{\mathrm{s}}=0.993, p<0.001$, maximum, $r_{\mathrm{s}}=0.993$, $p<0.001$, and minimum, $r_{\mathrm{s}}=0.977, p<0.001$, values). Moreover, a comparative study among bovine horse and wild boar dung, conducted in a protected area near Rome, revealed a remarkable higher proportion of this species in the omnivore (suine: $8.6 \%$ ) respect than in true herbivores (bovine: $0.7 \%$; equine: $3.8 \%$ ) (Carpaneto et al., unpublished data).

\subsection{Taxonomic composition}

The taxonomical analysis of the two allochronic communities, led to the following assessments (Fig. 2): (1) the unique species belonging to the family Geotrupidae (a tunneller, flightless species), which represented 7.1\% 


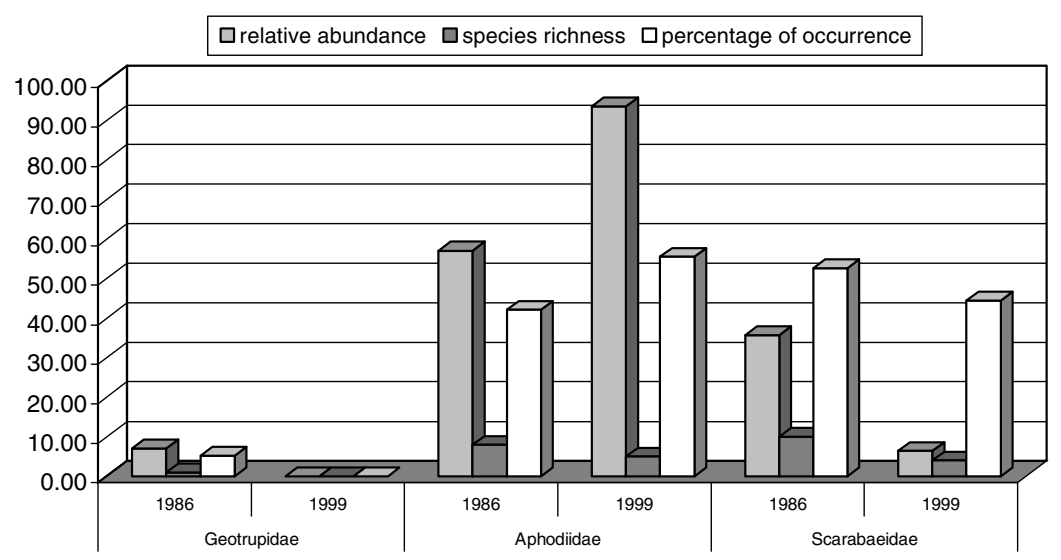

Fig. 2. Relative abundance, species richness and percentage of occurrence of each scarab beetle family in the two allochronic communities of the main study area (Pineto Park).

of the total abundance in 1986, is now locally extinct; (2) the number of species belonging to the family Aphodiidae (dwellers), was reduced from 8 to 5 , but their percentage of occurrence increased $(42.1 \%$ in 1986 and $55.6 \%$ in 1999), as well as their relative abundance (57.1\% in 1986, and $93.5 \%$ in 1999); (3) the number of species belonging to the family Scarabaeidae was reduced from 10 to 4 , and their percentage of occurrence decreased $(52.6 \%$ in 1986 , and $44.4 \%$ in 1999$)$ as well as their relative abundance $(35.7 \%$ in 1986 , and $6.5 \%$ in 1999). All the genera belonging to Scarabaeidae (except Onthophagus), recorded in 1986 (sheep dung), lack in the 1999 sampling (dog dung).

\subsection{Life-history strategies and adult phenology}

The scarab assemblage observed in 1986 (sheep dung) was characterised by a high percentage of occurrence for both tunnellers $(57.9 \%)$ and rollers $(5.3 \%)$, respect to values usually observed for these two categories in Italian dung beetle communities (Carpaneto and Piattella, 1990). In fact, tunnellers and rollers considered together represent $63 \%$ of the dung beetle species in this assemblage, and such value is high if compared with those observed in central Italy for all the species which relocate dung (median value $=44.88 \%$, 25th percentile $=39.23 \%$, 75th percentile $=48.19 \%) \quad($ Carpaneto and Piattella, 1990). In 1999, the scarab assemblage in dog dung of the Pineto Park was characterised by a similar percentage of tunnellers $(55.6 \%)$, and high in comparison with the percentage observed in the other nine Roman parks for sheep dung data (tunnellers median $=37.04 \%, 25$ th percentile $=30 \%, 75$ th percentile $=40.02 \%$ ), but roller species were not observed in any study area.

The two allochronic communities show a similar trend in the abundance of the most represented genera, Aphodius and Onthophagus, which also show a partial shift in adult phenology:
- the genus Aphodius, represented by dwellers (except for $A$. erraticus), shows an adult phenology from November to June;

- the genus Onthophagus, represented by tunnellers, shows an adult phenology from March to October.

Moreover, lower values of abundance were registered in the summer months (from June to September) for the genus Onthophagus in 1986 (minimum abundance $=45.45 \%$ ) respect to $1999 \quad$ (minimum abundance $=93.75 \%$ ).

\subsection{Comparison with other communities and similarity}

The comparison between the two allochronic communities in the Pineto Park and those observed in the other nine protected areas (sheep dung samples) of Rome revealed the following points:

(1) A lower species richness was registered in the Pineto Park in 1999 (20\% of the scarab dung beetle fauna of Rome) respect to the other nine protected areas (from $35 \%$ to $69 \%$ ).

(2) The scarab community associated with dog scats shows a lower diversity value for the Shannon-Wiener's index $(H=0.74)$ respect to the values registered in the other nine protected areas characterised by dung of domestic herbivores: in fact, the values for the nine areas of sheep dung range from 0.97 to 2.13 ; the values for the five areas of horse dung from 0.92 to 1.88 and the values for the two areas of cow dung from 1.72 to 2.56 .

(3) The dendrogram obtained from the values of Jaccard's index (Fig. 3) shows that the dog dung community of Pineto Park is located apart from the sheep/cow dung main cluster and excluded together with the majority of horse dung communities. Mean similarity values are lower between dog dung and all the other dung types (ovine, 


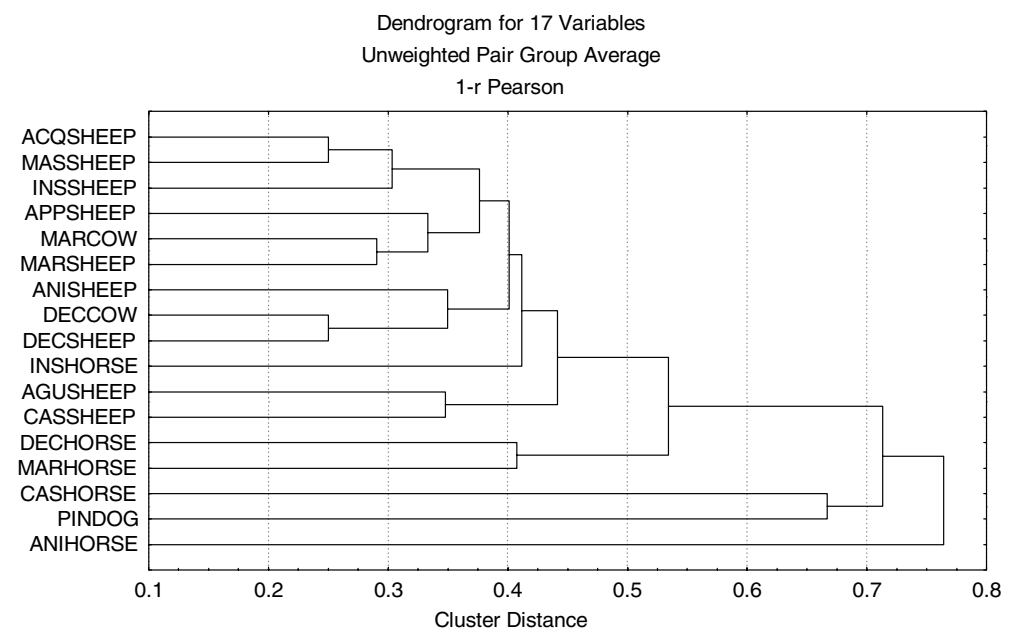

Fig. 3. Dendrogram yielded by hierarchical cluster analysis of similarity (Jaccard's index) among beetle assemblages associated to ovine, equine, bovine and canine dung in the main study area (Pineto Park) and other nine urban areas of Rome in 1999. See abbreviations in Section 2.

equine and bovine excrements) (Jaccard's mean value $=28.4 \%, \quad \mathrm{SD}=9.04 \%)$ respect to those among the three herbivore dung types (Jaccard's mean value $=50.9 \%, \mathrm{SD}=15.84 \%)\left(t_{135}=5.288\right.$, $p=0.001$, arcsine transformed data). Similarity between the two allochronic communities in the Pineto Park $(40.0 \%)$ is lower respect to similarity between the ovine dung community of the Pineto Park and the ovine dung communities of the other nine protected areas (Jaccard's mean value $=$ $49.2 \%, \mathrm{SD}=6.85 \%$ ) (Fig. 3).

(4) The species-area relationship among the 10 green urban areas (including Pineto Park sheep data from 1986) was not significant $\left(r_{\mathrm{s}}=0.571, p=0.084\right)$, in spite of the same kind of pasture habitat in each sampling area.

\section{Discussion}

\subsection{Richness, diversity and dominance}

The species richness recorded for dog dung in the Pineto Park (1999) is lower than that observed for sheep dung in the same area (1986). Moreover, it is also lower than the richness of all the other sheep dung assemblages in the nine Roman areas investigated.

A further evidence of the povery of species in dog dung is given by the low estimated number of species at the minimum number of individuals.

Values of $\Delta_{1}$ in the majority of the study areas are lower than $\Delta_{1}$ for the entire species pool, and show that an increase in species richness requires a higher increase in the sample size respect to the size requested for the whole sampling. Therefore, in these areas, individuals of different species were not homogeneously distributed among local samples.

The differences coming out from the comparison between the two allochronic dung beetle communities can be expressed by the following points:

(1) The decline of species richness and the tremendous increase of abundance, passing from sheep to dog dung in the Pineto Park, is an indicator of the reduced diversity of the community from 1986 to 1999.

(2) The absence of the two large body size species in 1999, S. laticollis and T. intermedius (respectively, a telecoprid and a paracoprid species), probably indicates their local extinction due to still unknown factors. These two species became rare in the whole urban area of Rome in the last decade (Carpaneto et al., unpublished data). A possible factor that reduced the populations of these species may be the increased predation rate by omnivorous and opportunistic birds, in particular the hooded crow, Corvus corone cornix Linnaeus 1758, and the starling, Sturnus vulgaris Linnaeus 1758. An interference in dung beetle activities by corvids was previously observed in Ireland (Gittings et al., 1994; Gittings and Giller, 1999). Another possible factor may be the incapacity of dog scats to sustain large size scarabs, as observed in Australia for carnivore scats: in fact, although numerous species of Australian scarab beetles feed on and bury the dung of introduced canids, none of the large size scarabs were recorded from carnivore scats (Faithfull, 1994). Let us remark that a decline of roller dung beetle populations was pointed out by Lobo (2001) in the Iberian Peninsula during the 20th century. 
(3) The reduced median value of the monthly diversity index was probably influenced by the change of food resource in the main study area, from sheep to dog dung.

(4) A neat increase of the annual abundance for some species was recorded. In particular, the increase in both rank abundance and adult phenology of $A$. johnsoni from sheep to dog dung is probably due to a preference of this species for dung of omnivore mammals. The same assumption is also valid for $O$. coenobita, often reported as a species associated to human and dog dung (Goljan, 1953; Horion, 1958; Lumaret, 1990). In fact, domestic and vagrant dogs have a mixed diet similar to humans. In our case, large catches of an autumnal species (A. johnsoni) depressed the rank abundance of all the other species in the pooled catch (Finn et al., 1998). However, it should be kept in mind that, as proved by recent studies on dung beetle ecology, both dung type and dung quality (defined by chemical parameters and age) may correspond to a different abundance of Aphodius species (Finn and Giller, 2002) as well as to their biological characteristics, such as oviposition behaviour (Gittings and Giller, 1998).

The presence of two specimens of $A$. foetidus, a species not found in Pineto Park (1999), was probably casual. This species did never demonstrate any preference for a particular dung type in Italy (unpublished data).

\subsection{Life-history strategies and adult phenology}

The high percentage of occurrence for roller and tunneller species in the Pineto park can be explained in two different ways for the two allochronic assemblages:

- In 1986, the main cause was probably the scarcity of grazing animals, and the consequent food shortage for dung beetles, which produced an increased competition. In such ecological context, rollers and tunnellers could have obtained a higher reproductive success respect to dwellers. In fact, because of their ability in digging subterranean nests or making nests at pad/soil interface, they rapidly bury dung and remove it, avoiding competition with other species (Krell-Westerwalbesloh et al., 2004).

- In 1999, it could be a consequence of two jointed factors: (1) the scarcity of food resource and (2) the higher dehydration rate of dog dung. In fact, dog dung is scarce and has a rough structure (hair and undigested vegetable matter), two features which favour species that immediately bury dung reserves. The absence of competitively superior species such as telecoprids in this contest could be explained by the high predation rate by corvids or by the incapacity of dog scats to sustain large size scarabs (see Section 4.1).

The different adult phenology observed for the genera Onthophagus and Aphodius is congruent with the ecobiogeographical features of these two genera: Onthophagus belongs to Scarabaeidae, a family mainly distributed in the tropics; Aphodius belongs to Aphodiidae, a family mainly distributed in the northern hemisphere (Cambefort, 1991). The lower abundance of the genus Onthophagus may be a consequence of the contemporary presence of the genus Euoniticellus in $1986\left(r_{\mathrm{s}}=0.597\right.$, $\mathrm{df}=12, p=0.04)$.

\subsection{Comparison with other communities and similarity}

The low similarity between dog dung and herbivore dung (Fig. 3) in the present work is a consequence of the poverty found in the first one, both in richness and diversity.

The poverty of species observed in the two allochronic communities in the Pineto Park, respect to the sheep dung communities of the nine Roman areas, cannot be correlated to a little size of the area and habitat heterogeneity, but is probably correlated to food shortage (scarcity of sheep dung in 1986) and to the peculiarities of dog dung (the only resource occurring in 1999). Reduction in dung availability, very often occurring in urban pastures in Rome, can lead directly to reduction in reproductive output of adults through interference or exploitation competition (Giller and Doube, 1994). Moreover, the further decrease of species richness observed in 1999 may be explained by dog dung peculiarities. Canine scats undergo a quicker alteration of microclimatic conditions because of their coarse structure due to a short time of digestive processing of the fibres (Janis, 1976). These conditions can negatively affect the reproductive success of Aphodius species, whose larvae develop within the dung pad (Holter, 1979). On the contrary, the success of tunnellers is due to their habits of securing food under the soil surface as soon as available.

The investigations on dung beetles associated to dog scats are very few and gave results quite different in relation with ecological and geographic conditions. In India, the guilds occurring in dog and human dung showed a high similarity and were quite distinct from the guilds associated to herbivores (Oppenheimer and Begum, 1978). Some species of Onthophagus (such as O. duporti, O. bifasciatus, O. luridipennis) were abundant in dog/human dung and scarce or absent in cattle dung; on the contrary, other species of the same genus (O. triceratops, $O$. aenescens, $O$. ramosellus, $O$. gazella) revealed a clearcut preference for cattle. A recent paper conducted in Taiwan (Huang et al., 2001) pointed out the reproductive success of a local roller species, Paragymnopleurus 
sinuatus (Olivier, 1789), when it uses the dung of omnivore species such as human and dog. In southern Georgia, USA, dog scats attracted a scarce number of species and specimens respect to other dung types (Fincher et al., 1970). In Australia, Onthophagus auritus, a native species usually collected in dog scats and carrions, demonstrated a preference for a microhabitat similar to $O$. coenobita, characterised by "well shaded" areas such as forests and woodlands on sandy and loamy soils (Faithfull, 1994). In Africa, many species of dung beetles are specialised to use only large herbivore dung pats, but other species are exclusively found on smaller and nitrogen rich faeces of omnivore mammals, with Onthophagus species having the latter preference (Cambefort and Walter, 1991). A recent study on the spotted hyaena scats in Ivory Coast showed that these are exploited mainly by few lamellicorn beetles (Omorgus, Anachalcos, Onthophagus) that feed on carrion or are at least facultatively necrophagous (Krell et al., 2003). In southern Spain (Doñana National Park), species composition, diversity and similarity in herbivore vs. carnivore dung were compared (Martin-Piera and Lobo, 1996) by the analysis of the dung beetle asssociated to five species of ungulates (horse, cow, wild boar, deer, fallow deer), three of carnivores (badger, lynx and red fox) and man. According to these data, only one species, Typhaeus momus, was found in all the dung types; 20 species were found in human dung $(57 \%$ of the whole scarab beetle community sampled there), that is a number very near to that collected in ungulate dung (from 18 to 24 species); only one species was found in carnivore dung (lynx and fox). At Doñana, similarity among dung beetle assemblages in domestic herbivores was about $53.0 \%$, while similarity between assemblages in domestic herbivores and assemblages in carnivores was less than 5.0\%. The first value is approximately the same observed in the present paper among domestic herbivores in Roman countryside; on the contrary, the second one (herbivores vs. wild carnivores) is very different from that observed in our study areas (herbivores vs. dog). In fact, dog dung harbours a higher number of scarab species respect to other wild carnivores. Such a difference may be explained by the fact that, at least in urban areas, dogs have not a true carnivore diet but an omnivorous one, as they mainly eat leftovers of human food with a high content of cellulose and/or other carbohydrates.

Another carnivore whose diet is omnivorous is the brown bear ( $U$. arctos Linnaeus, 1758). It so happens that the brown bear dung harbours a rich community of scarab beetles. A research conducted in the Abruzzi National Park (Carpaneto and Fabbri, 1984) revealed the occurrence of 19 scarab species (four Scarabaeidae and 15 Aphodiidae) in brown bear dung collected on mountain habitats, especially beech forest and its clearings. Such guild includes almost all the dung beetle species living in these habitats, usually found on cow, sheep and horse dung. This evidence is a consequence of the true omnivorous diet of the brown bear.

\section{Conclusions}

Dog faeces are not only a hygienic problem in urban areas (particularly if not dismantled by dung beetles), but also the most abundant resource for dung beetles. At present, dog dung in the Pineto Park is the sole food resource that can support a scarab dung beetle community, after the removal of both wild and domestic herbivores. Therefore, a reduced green area crossed by dogs could provide a temporary refuge for some species of dung eaters that otherwise may encounter local extinction in urban environments. Furthermore, dog scats may favour some rare species that prefer the dung of omnivorous animals (like $O$. coenobita and A. johnsoni in the main study area). The current situation could allow the maintenance of scarab beetle metapopulations in urban areas until these will undergo an ecological restoration.

\section{Acknowledgements}

We are grateful to Marco A. Bologna, scientific coordinator of the research line "Fauna and Zoocenosis" partially financed by the regional agency RomaNatura for the Management Plan of the Protected Areas of Rome. A special thank is also due to Simone Fattorini for his precious help in data elaboration. This research was also supported by a grant from MIUR (Ministry of Instruction, University and Research).

\section{References}

Barbero, E., Palestrini, C., Rolando, A., 1999. Dung beetle conservation: effects of habitat and resource selection (Coleoptera, Scarabaeoidea). Journal of Insect Conservation 3, 75-84.

Cambefort, Y., 1991. Biogeography and evolution. In: Hanski, I., Cambefort, Y. (Eds.), Dung Beetle Ecology. Princeton University Press, Princeton, NJ, pp. 51-67.

Cambefort, Y., Hanski, I., 1991. Dung beetle population biology. In: Hanski, I., Cambefort, Y. (Eds.), Dung Beetle Ecology. Princeton University Press, Princeton, NJ, pp. 36-50.

Cambefort, Y., Walter, P., 1991. Dung beetles in tropical forests in Africa. In: Hanski, I., Cambefort, Y. (Eds.), Dung Beetle Ecology. Princeton University Press, Princeton, NJ, pp. 198-210.

Carpaneto, G.M., Fabbri, M., 1984. Coleotteri Scarabaeidae e Aphodiidae coprofagi associati agli escrementi dell'Orso Marsicano (Ursus arctos marsicanus Altobello) nel parco nazionale d'Abruzzo (Coleoptera). Bollettino dell'Associazione Romana di Entomologia 38, 31-45.

Carpaneto, G.M., Piattella, E., 1990. Competizione interspecifica e andamento stagionale di una comunità coprofaga in un'area verde urbana di Roma. Bollettino dell'Associazione Romana di Entomologia 44, 67-79. 
Carpaneto, G.M., Piattella, E., 1997. Coleoptera Lucanoidea, Scarabaeoidea. In: Zapparoli, M. (Ed.), Gli Insetti di Roma, Fratelli Palombi Editori, Roma, pp. 154-165.

Desender, K., Turin, H., 1989. Loss of habitats and changes in the composition of the ground and tiger beetle fauna in four West European countries since 1950 (Coleoptera: Carabidae, Cicindelidae). Biological Conservation 48, 277-294.

Faithfull, I., 1992. Records of native dung beetles Onthophagus pexatus Harold, O. auritus Erichson and O. granulatus Boheman (Coleoptera: Scarabaeidae) at dog scats and their potential for biocontrol of dog dung. Victorian Entomologist 22 (5), 105-108.

Faithfull, I., 1994. Further record and observations of dung beetles (Coleoptera: Scarabaeinae) at carnivore dung in eastern Australia. Victorian Entomologist 24 (3), 63-67.

Fincher, G.T., Stewart, T.B., Davis, R., 1970. Attraction of coprophagous beetles to feces of various animals. Journal of Parasitology 56, 378-383.

Finn, J.A., Giller, P.S., 2002. Experimental investigations of colonisation by north temperate dung beetles of different types of domestic herbivore dung. Applied Soil Ecology 20, 1-13.

Finn, J.A., Gittings, T., 2003. A review of competition in north temperate dung beetle communities. Ecological Entomology 28, 113.

Finn, J.A., Gittings, T., Giller, P.S., 1998. Aphodius dung beetle assemblage stability at different spatial and temporal scales. Applied Soil Ecology 10, 27-36.

Giller, P.S., Doube, B.M., 1994. Spatial and temporal co-occurrence of competitors in Southern African dung beetle communities. Journal of Animal Ecology 63, 629-643.

Gittings, T., Giller, P.S., 1998. Resource quality and the colonisation and succession of coprophagous dung beetles. Ecography 21, 581592.

Gittings, T., Giller, P.S., 1999. Larval dynamics in an assemblage of Aphodius dung beetles. Pedobiologia 43, 439-452.

Gittings, T., Giller, P.S., Stakelum, G., 1994. Dung decomposition in contrasting temperate pastures in relation to dung beetle and earthworm activity. Pedobiologia 38, 455-474.

Goljan, A., 1953. Studies on polish beetles of the Onthophagus ovatus (L.) group with some biological observations on coprophagans (Col., Scarabaeidae). Annales Musei Zoologici Polonici 25, 55-81.

Halffter, G., Matthews, E.G., 1966. The natural history of dung beetles of the subfamily Scarabaeinae (Coleoptera, Scarabaeidae). Folia Entomologica Mexicana 12-14, 1-312.

Hancox, M., 1991. The insect fauna of badger dung. Entomologist's Monthly Magazine 127, 251.

Heck Jr., K.L., Van Belle, G., Simberloff, D., 1975. Explicit calculation of the rarefaction diversity measurement and the determination of sufficient sample size. Ecology 56, 1459-1461.

Holter, P., 1979. Abundance and reproductive strategy of the dung beetle Aphodius rufipes (L.) (Scarabaeidae). Ecological Entomology $4,317-326$.

Horion, A., 1958. Faunistik der Mitteleuropäischen Käfer. Band VI: Lamellicornia. Kommissionsverlag Buchdruckerei Aug. Feyel, Ueberlingen-Bodensee, Germany.
Huang, M.-S., Shieh, B.-S., Liang, S.-H., 2001. Food selection and reproductive success of Paragymnopleurus sinuatus on three kinds of dung. Formosan Entomology 21, 329-337.

Hurlbert, S.H., 1971. The nonconcept of species diversity: a critique and alternative parameters. Ecology 52, 577-586.

Janis, C.M., 1976. The evolutionary strategy of the Equidae and the origins of rumen and cecal digestion. Evolution 30, 757-774.

Krell, F.-T., Korb, J., Walter, P., 2003. The beetle fauna of the hyaena latrines: coprocenoses consisting of necrophagous beetles (Coleoptera Trogidae Scarabaeidae). Tropical Zoology 16, 145-152.

Krell-Westerwalbesloh, S., Krell, F.-T., Linsenmair, K.E., 2004. Diel separation of Afrotropical dung beetle guilds-avoiding competition and neglecting resources (Coleoptera: Scarabaeoidea). Journal of Natural History 38, 2225-2249.

Landin, B.-O., 1961. Ecological studies on dung beetles (Col. Scarabaeidae). Opuscula Entomologica (Supplementum) 19, 1-277.

Lobo, J.M., 2001. Decline of roller dung beetle (Scarabaeinae) populations in the Iberian Peninsula during the 20th century. Biological Conservation 97 (1), 43-50.

Lumaret, J.P., 1990. Atlas des Coleopteres Scarabeides Laparosticti de France. Museum National d'Histoire Naturelle, Paris.

Lumaret, J.P., Kadiri, N., Bertrand, M., 1992. Changes in resources: consequences for the dynamics of dung beetle communities. Journal of Applied Ecology 29, 349-356.

Martin-Piera, F., Lobo, J.M., 1996. A comparative discussion of trophic preferences in dung beetle communities. Miscellania Zoologica 19, 13-31.

Mysterud, I., Wiger, R., 1976. Beetle fauna associated with scats of Brown bear (Ursus arctos) from Trysil, South Norway 1974. Norwegian Journal of Entomology 23, 1-5.

Olszewski, T.D., 2004. A unified mathematical framework for the measurement of richness and evenness within and among multiple communities. Oikos 104, 377-387.

Oppenheimer, J.R., Begum, J., 1978. Ecology of some dung beetles (Scarabaeidae and Aphodiidae) in Dacca District. Bangladesh Journal of Zoology 6, 23-29.

Pyle, R., Bentzien, M., Opler, P., 1981. Insect conservation. Annual Review of Entomology 26, 233-258.

Rojewski, C., 1983. Observations on the nesting behaviour of Aphodius erraticus (L.) (Coleoptera, Scarabaeidae). Polskie Pismo Entomologiczne 53, 271-279.

Sanders, H.L., 1968. Benthic marine diversity: a comparative study. American Naturalist 102, 660-668.

Turin, H., den Boer, P.J., 1988. Changes in the distribution of carabid beetles in The Netherlands since 1880 II. Isolation of habitats and long term time trend in occurrence of carabid species with different powers of dispersal (Coleoptera, Carabidae). Biological Conservation 44, 179-200.

van Swaay, C.A.M., 1990. An assessment of the changes in butterfly abundance in The Netherlands during the 20th century. Biological Conservation 52, 287-302.

Vitner, J., 1998. Reproductive biology of the Central European Aphodius species with large scutellum (Coleoptera: Scarabaeidae: Aphodiinae). Acta Societatis Zoologicae Bohemicae 62, 227-253. 